\title{
Olhares para o Retorno do Pêndulo: reflexões a partir de Bauman e Dessal
}

\author{
Sirlei Tedesco"
}

Universidade de Caxias do Sul, Doutoranda do Programa de Pós-graduação em Educação

Geraldo Antônio da Rosa²

Universidade de Caxias do Sul, Professor do Programa de Pós-Graduação na Universidade de Caxias do Sul

DESSAL, Gustavo; BAUMAN, Zygmunt. 0 Retorno do Pêndulo: sobre a Psicanálise e o Futuro do Mundo Líquido. Tradução: Joana Angélica D’Ávila Melo. Rio de Janeiro: Zahar, 2017.

Segurança contrapondo-se à ausência de liberdade, aflição do homem no mundo líquido e sua busca por identidade, fragilidade das relações humanas, neocapitalismo e seus efeitos perversos são temas que acompanham a humanidade desde a contemporaneidade. Diante desse contexto, é indispensável a provocação para um diálogo sobre o conceito de "liquidez". Proposto por Bauman como paradigma do novo século, além de ferramenta para pensar o hoje, faz grande aproximação com algumas considerações atestadas pelo psicanalista Sigmund Freud, no século passado, ademais de possibilitar frutíferas relações com a globalização e a metamorfose das relações de poder entre o Estado e o capital.

Sociólogo, pensador, professor e escritor polonês, Zygmunt Bauman destaca-se por ser uma das vozes mais críticas da sociedade contemporânea. É considerado expoente da chamada "sociologia humanística", contribuindo com seu vasto trabalho acadêmico e inúmeros estudos publicados. É analista de temas contemporâneos, como política, amor, comunidade, trabalho, consumo, identidade, tempo, entre outros. Com sua obra para a compreensão das relações por meio do conceito de liquidez, tornou-se um dos teóricos proeminentes da pósmodernidade.

Gustavo Dessal é psicanalista e escritor, membro da Associação Mundial de Psicanálise e docente do Instituto do Campo Freudiano na Espanha. É autor de numerosas publicações.

Com a preocupação de fazer um esforço de síntese e eludir as simplificações, apresentamos a obra 0 Retorno do Pêndulo: sobre a Psicanálise e o Futuro do Mundo Líquido. Seus autores, Bauman e Dessal, constroem nesse escrito um discurso com aproximações e

Mestre em Educação pela Pontificia Universidade Católica do Rio Grande do Sul; Doutoranda em Educação pela Universidade de Caxias do Sul; https://orcid.org/0000-0001-7408-4962; http://lattes.cnpq.br/3077309397102537.

2 Doutor em Teologia pelas Faculdades EST, RS; Pós-Doutor em Humanidades pela Universidade Carlos III, Madri, Espanha; https://orcid.org/0000-0002-1193-7910; http://lattes.cnpq.br/4290166533847099. 
divergências entre a sociologia e a psicanálise, tomando como pontos de partida o conceito de liquidez e o pensamento de Sigmund Freud, especialmente as teses desenvolvidas na obra O Mal-Estar na Civilização, de 1929, como disparadoras da discussão.

0 título original da obra, El retorno del péndulo (Sobre psicoanálisis y el futuro del mundo líquido), teve sua tradução autorizada em espanhol e publicada em 2014 pelo Fundo de Cultura Econômica, de Madri, Espanha. A primeira tradução para o português foi realizada por Joana Angélica d'Avila Melo e publicada pela editora Zahar em 2017.

A obra inclui quatro artigos de Zygmunt Bauman, intercalados por comentários de Gustavo Dessal. Tal corpus inter-relaciona dois ramos do saber - Sociologia e Psicologia - propondo reflexões primordiais do mundo contemporâneo, conjecturando um movimento pendular que oscila entre o desejo de se conquistar mais liberdade e o anseio por dispor de segurança, um deslocamento seminal a que Bauman chamou de "fase líquida da modernidade".

No primeiro artigo, intitulado Liberdade e segurança: um caso de Hassliebe (relação de amor e ódio), Bauman, ao destacar da tese de Freud (1929, p. 15) que "é muito menos difícil experimentarmos a infelicidade" contribui trazendo três causas das quais tememos que advenha o sofrimento: a supremacia da natureza, a fragilidade do nosso corpo e a insuficiência das normas que regulam os vínculos recíprocos entre os seres humanos.

Na sequência, com o comentário sobre Liberdade e segurança: um caso de Hassliebe, Dessal responde, fundamentado em Ulrich Beck, esclarecendo que o indivíduo pós-moderno é aquele que se vê obrigado a buscar soluções biográficas para problemas sistêmicos. Reforça que o mais temível é aquele que nos espreita de dentro de nós mesmos, a que Freud denomina "pulsão de morte".

No artigo A civilização freudiana revisitada, ou 0 que se supõe ter acontecido com o princípio de realidade?, Bauman retoma os escritos de Freud, cerca de 80 anos depois, e recorda-nos que eles já ressaltavam que o domínio da massa por uma minoria continuará imprescindivel, bem como a imposição coercitiva do trabalho cultural. Assim, a passagem de uma sociedade de produtores - trabalhadores e soldados - para uma sociedade de consumidores decretou indivíduos viciados em adaptação. De certa forma, entende-se que as identidades devem ser descartáveis. Uma identidade insatisfatória ou, ainda, uma identidade que denote idade avançada ao ser comparada com as identidades "novas e melhoradas", disponíveis no presente, deve ser fácil de abandonar. Além disso, a vida da geração jovem é vivida em um estado de emergência perpétua.

No comentário sobre $A$ civilização freudiana revisitada, ou 0 que se supõe ter acontecido com o princípio de realidade?, Gustavo Dessal ressalta que a Sociologia, na melhor e mais nobre tradição de Durkheim, permite-nos compreender a sociedade como organismo 
vivo e não como conceito abstrato - uma sociedade na qual a lógica coletiva não pode deixar de lado tudo aquilo que Freud nos revelou acerca do sujeito.

0 painel de Freud (resposta ao painel) é um artigo no qual Bauman se coloca como crítico e beneficiário devoto do pensamento de Freud, pois esclarece os usos sociais, políticos e econômicos do cambiante equilibrio entre o princípio do prazer e o princípio de realidade.

Para o pensador, existe a perpetuidade do deslocamento segurança-liberdade como um sintoma de otimismo excessivo e injustificado. A história da humanidade está salpicada de falsas alvoradas. Por consequência, está também replena de falsas esperanças, vezada a vislumbrar, a cada nova oportunidade, o anúncio de que os problemas ou mal-estares atuais ficarão para trás. Essa inclinação se institucionalizou na era moderna, mediante a associação entre a ideia de progresso e o culto à ciência e à tecnologia, motor da sociedade de consumo.

Com relação a esse aspecto, Bauman enfatiza que as inovações tecnológicas podem desacelerar ou tornar mais errática a oscilação do pêndulo, mas é sumamente improvável que a detenham e mais ainda que a tornem perpétua.

Com sua proverbial modéstia, discorre que perto do fim de uma vida de estudos, chega à conclusão de que a liberdade e a segurança, duas forças titânicas em cujo épico duelo Freud detectou a origem da "civilização", constituem valores igualmente indispensáveis para uma vida satisfatória, porém excessivamente difíceis de reconciliar. Sua relação dialética constitui um traço antropológico do animal social conhecido como Homo Sapiens.

A liberdade e a segurança não podem sobreviver uma sem a outra, tampouco podem conviver em paz. É muito improvável que um dia seja encontrado "o ponto médio", isto é, o equilibrio, mas ainda assim sua busca jamais cessará. 0 movimento pendular é o resultado dessa aporia.

Ao finalizar o artigo, faz a provocação de que o pensamento utópico é um companheiro inseparável da vida moderna. "Utopias iconoclastas" são a possibilidade de uma realidade alternativa, uma sociedade superior composta por neo-humanos.

Em seguida, no comentário sobre 0 painel de Freud, Dessal enfatiza em seu discurso breves esclarecimentos acerca do conceito do prazer. Para o autor, a ideia de que a vida psíquica é regida pelo princípio do prazer foi uma das hipóteses de Freud, com escritos apoiados em considerações teóricas que parodiavam a literatura científica da época. No célebre texto Projeto para uma psicologia científica (1895), em um esforço para empregar uma linguagem neurológica, Freud insinua a escolha decisiva que o encaminhou para a descoberta do inconsciente - usou a linguagem poética para dizer que se decidiu pelas palavras em vez de neurônios, com o propósito de fazer da psicanálise uma ciência. 0 princípio de realidade é o prolongamento do princípio do prazer, que, por sua vez, tem o papel fundamental de 
assegurar que os desejos sigam uma rota mais afastada da via alucinatória. A ideia de que a realidade superaria o princípio do prazer era para Freud algo inconcebível.

Dessal entende a realidade como um âmbito de significações impossíveis de universalizar, embora exista uma compreensão comum de identificação de certas circunstâncias que compartilhamos como algo semelhante a uma objetivação do mundo.

Com relação ao tema da pulsão de morte, faz um comentário à obra de Bauman Modernidade e Holocausto, na qual o pensador polonês percebeu, com toda a clareza, que a catástrofe não é um acidente no programa da racionalidade técnico-científica, senão que the é intrínseca.

Concluindo, Dessal enfatiza sua decepção ao dizer que não nos podemos furtar à evidência de que Auschwitz foi a festa da inauguração de um novo paradigma histórico, no qual a ideologia do progresso desencerrou seu sentido mortal.

No artigo Procurando na Atenas moderna uma resposta à antiga pergunta de Jerusalém, Bauman inicia trazendo as narrativas do Livro de Jó com sua teoria política para o judaísmo e, por meio dele, para o cristianismo, quanto à onipotência de Deus.

Em um texto profundamente provocador, constrói aproximações com grandes pensadores. Inicialmente toma por base o Livro de Jó para discutir as ideias de Carl Schmitt sobre soberania do governante, no qual o jurista alemão teria inculcado uma visão préformada da ordem divina no campo da ordem legislativa do Estado. Posteriormente observa a "inclinação totalitária" por meio do pensamento de Hannah Arendt, discute a natureza da soberania, a partir do discurso de Jean-Jacques Rousseau, e evoca a sabedoria de que tudo é natural, tomando o exemplo do desastre de Lisboa e de suas consequências catastróficas, que foram fatos relacionados aos seres humanos, não à natureza, tratando-se, pois, de culpa e não pecado.

Bauman prossegue suas aproximações com uma pluralidade de autores. Em Max Weber, busca a descrição de Entzauberung, ou "desencanto" da natureza, despindo-a de seu disfarce divino. Para o autor polonês, no entanto, embora agora os seres humanos estejam no comando, a incerteza e os medos cósmicos não se desvaneceram. Então, a natureza é concebida como uma perturbação temporária e a perspectiva de controle dela era apenas questão de tempo. Concorda com Immanuel Kant que, ao empregarmos a razão, podemos elevar a avaliação moral e o tipo de comportamento que desejamos universalmente, seguindo a categoria de lei natural. Assim esperava-se que os humanos, no início da era moderna, desenvolvessem-se luminarmente. Porém, o que se constata é que os desastres provocados por ações imorais humanas parecem ser cada vez menos administráveis.

Ainda, contribui refletindo sobre potenciais terroristas e suas bombas "assustadoramente fáceis de montar" (quando se trata do emprego dos medos difusos 
para fertilizar as vinhas da ira, a lógica é irrelevante). Sob a égide da condução a uma guerra ao terrorismo, descreve um mapa rodoviário para o totalitarismo (tortura, vigilância, perseguição). Ao trazer Henry A. Giroux, assinala novas geografias da exclusão e novas paisagens abastadas em uma ordem mundial. Bauman também busca fundamentação em Giorgio Agamben na sinalização de que o estado de exceção tende cada vez mais a parecer o paradigma predominante do governo na política contemporânea. Ao finalizar com a ideia de Stálin, emprega o conceito de "medo oficial" a serviço do poder do Estado.

Para finalizar a etapa da obra constituída por artigos e comentários, no seu comentário sobre Procurando na Atenas moderna uma resposta à antiga pergunta de Jerusalém, Gustavo Dessal aponta em Freud a descoberta de que a satisfação no ser humano não é malograda por motivos externos, que podem intervir como fatores contingentes. É preciso incluir o fato de que a necessidade primária, ao atravessar o labirinto da linguagem, faz surgir a dimensão do Outro.

Na segunda parte da obra, encontram-se correspondências entre Zygmunt Bauman e Gustavo Dessal, do período entre julho e agosto de 2012, constituídas de potência e imersão entre os discursos da Psicologia e da Sociologia, visando a um pensar sobre os problemas do mundo contemporâneo.

Certamente, 0 Retorno do Pêndulo: sobre a Psicanálise e o Futuro do Mundo Líquido pode ser considerado um livro inesgotável, que comove a cada página lida, levando o leitor à necessária e inesgotável reflexão sobre sua condição de humano. Hoje, é possível que estejamos vivendo uma nova inversão pendular. 0 que essa guinada pode nos trazer no futuro? Entre tantos temas tão caros ao sociólogo polonês, Bauman e a contribuição de Dessal nos possibilitam um horizonte memorável sobre o pensamento de Freud na perspectiva de liquidez contemporânea. 0 grande diferencial desse livro é, sem dúvida, o fato de ser constituído por artigos e respectivos comentários, além de cartas constituídas por reflexões consistentes, que servem para nos dizer dos caminhos que, enquanto humanidade, temos trilhado pela conquista e manutenção da liberdade em tempos tão liquefeitos.

Endereços para correspondência: Rua Eduardo Reginato, 48/302, Bairro Valverde, 95330-000, Veranópolis, Rio Grande do Sul, Brasil; sirtedesco@gmail.com 
